\title{
Factors Associated with Mortality of TB/HIV Co-infected Patients in Ethiopia
}

\author{
Alula M. Teklu ${ }^{1}$, Abiy Nega ${ }^{2}$, Admasu Tenna Mamuye ${ }^{3}$, Yohannes Sitotaw ${ }^{4}$, \\ Desta Kassa ${ }^{5}$, Getnet Mesfin ${ }^{6}$, Bekele Belayihun ${ }^{7}$, Girmay Medhin ${ }^{8}$, \\ Kesetebirhan Yirdaw9
}

\footnotetext{
OPEN ACCESS

Citation: Alula M. Teklu, Abiy Nega, Admasu TennaMamuye, et al. Factors Associated with Mortality of TB/HIV Co-infected Patients in Ethiopia. Ethiop J Health Sci 2017;27(si1):29-38. doi: http://dx.doi.org/10.4314/ejhs.v27i1.4S.

Received: February 1, 2016

Accepted: August 12, 2016

Published: March 15, 2017

Copyright: () 2017 Alula MT et al. This is an open access article

distributed under the terms of the Creative Commons Attribution

License, which permits unrestricted use, distribution, and

reproduction in any medium, provided the original author and source are credited.

Funding:Center for Disease Control and Prevention (CDC)

Competing Interests: The authors declare that this manuscript was

approved by all authors in its form and that no competing interest

exists.

Affilation and Correspondence:

${ }^{1}$ Alula M. Teklu: MERQ Consultancy Services, Addis Ababa, Ethiopa

${ }^{2}$ Abiy Nega: MERQ Consultancy Services, Addis Ababa, Ethiopia

${ }^{3}$ Admasu Tenna Mamuye: Addis Ababa University, Medical

Faculty, Addis Ababa, Ethiopia

${ }^{4}$ Yohannes Sitotaw: Ministry of Science and Technology, Addis

Ababa, Ethiopia

${ }^{5}$ Desta Kassa: Ethiopian Public Health Institute, Addis Ababa,

Ethiopia

${ }^{6}$ Getnet Mesfin: Ethiopian Public Health Institute, Addis Ababa,

Ethiopia

${ }^{7}$ Mekele Belayhiun: Ethiopian Public Health Association, Addis

Ababa, Ethiopia

${ }^{8}$ Girmay Medhin: Aklilu Lemma Institute of Pathobiology, Addis Ababa

${ }^{9}$ Kesetebirhan Delele: South Africa University, Addis Ababa, Ethiopia

* Alula M. Teklu, E-mail: ateklu72@gmail.com
}

\begin{abstract}
Background: Despite the large number of TB patients on ART in Ethiopia, their mortality remains high. This study reports the effect of TB on HIV related mortality and determinants of TB/HIV co-infection related mortality.

Methods: A longitudinal study design was employed as part of the Advanced Clinical Monitoring of ART (ACM) in Ethiopia. All patients started on ART at or after January 1, 2005 were included. Survival analysis was done to compare survival patterns of HIV patients with $T B$ against HIV patients without TB. In addition, determinants of survival among TB/HIV coinfected patients were analyzed. Adjusted effects of the different factors on time to death were generated using Cox-proportional hazards regression.

Results: A total of 3,889 patients were enrolled in the ACM study, of which 355 TB cases were identified, making the crude prevalence $9 \%(95 \%$ CI 8.3 - 10.2). Overall, incidence of TB was 2.2 (95\% CI 1.9-2.4) per 100 person-years. TB was highest in the first 2 months and declined with time on ART to reach 1 per 100 person years after 24 months on ART. TB was significantly associated with mortality among HIV patients on HAART (AHR 2.0, 95\% CI 1.47-2.75). Male gender was associated with mortality among TB/HIV co-infected patients.

Conclusion: Tuberculosis plays a key role in HIV associated mortality. Targeted interventions which can keep patients free of TB in the early stages of their treatment are required to reduce $T B$ related mortality.

Key Words: Tuberculosis, Antiretroviral therapy, Mortality
\end{abstract}




\section{INTRODUCTION}

People living with HIV (PLHIV) and latent tuberculosis infection (LTBI) are at much higher risk for progressing to active $\mathrm{TB}$ disease than people with latent TB infection alone. TB remains a major illness for people living with HIV/AIDS (PLHIV) (1). According to the World Health Organization (WHO), of the 9 million new TB cases in 2009, more than 1.2 million (13\%) were PLHIV (2). While PLHIV accounts for only $0.5 \%$ of the world population, $13 \%$ of TB cases across the globe are among those with PLHIV. Even though there is an improvement in the actual number of TB cases, the 2014 WHO global report states that out of the 9 million who fell ill with TB in 2013, 1.1 million (12.2\%) were PLHIV. The same report showed that 1.5 million people died from TB, out of which 360,000 (24\%) were PLHIV. Ethiopia is among the sub Saharan African countries characterized by a high burden of TB as well as HIV (3).

The WHO recommends that all TB patients with HIV should be started on antiretroviral therapy (ART) irrespective of their CD4 count(1) because ART reduces mortality by $64-95 \%$.(4) According to the national annual performance report of Ethiopia, $70 \%$ of TB patients with HIV were put on ART (5), but the mortality in TB/HIV co-infected patients remains high even after starting ART. Several factors have been identified that contribute to the high mortality rate, including low baseline CD4 count, having advanced disease at start of treatment and not receiving treatment(6). Most previous studies addressing TB related HIV deaths have focused only on assessing the relative contribution of TB to HIV related mortality. $(7,8)$ Also, most studies assessing TB burden among those with PLHIV used secondary data generated during routine service delivery, making disease burden quantification less reliable. (7-10).

In the current study, the aim was to examine TB disease burden, the association of TB and HIV related mortality, and identify the determinants of mortality among those with TB/HIV co-infection in seven university teaching hospitals in Ethiopia. These hospitals are part of the clinical cohort network called the advanced clinical monitoring of ART in Ethiopia (ACM) and the data used for the current study were extracted from the ACM database.

\section{METHODS}

Study population: The study population was HIV patients on ART who were diagnosed with TB disease in the seven teaching and-referral hospitals which were included in the ACM project. All patients who started ART since 2005 including those treated for TB during ART initiation or afterwards were included.

Study design: The study employed a longitudinal study design. Study subjects were enrolled using a random selection of the advanced clinical monitoring of ART clinical cohort (at the initiation of the study). All patients who started ART on or after January 1, 2005 were eligible. Both ART-experienced and ART-naïve patients were enrolled via random selection, after informed consent was obtained. Data were collected using routine program monitoring tools as well as study specific tools. Retrospective data collection through chart review was done for all ARTexperienced patients. All data collection was done after securing ethical clearance from regulatory bodies and all patients who were elgible were approached for informed consent and those who consented were included into the cohort. Patients who were dead at the time of sampling were also included if randomly selected.

Variables and Statistical Analysis: TB diagnosis was determined using the Ethiopian national guideline where at least 2 sputum smears are required for all pulmonary $\mathrm{TB}$ suspects and relevant tests are done for extra-pulmonary $\mathrm{TB}$ cases (11). TB disease burden was estimated using prevalence estimate as well as incidence rate using person-time as a denominator. Incidence rate was measured at different time periods after ART initiation.

Data was analyzed using STATA version 12. Tables and figures describe the composition and structure of participants by key baseline clinical and demographic characteristics. Bi-variable analysis was performed to evaluate association of selected potential factors (i.e., age, gender, WHO Stage at baseline, cotrimoxazole and baseline CD4 count) with mortality. Kaplan-Meier survival curves were used to compare survival patterns of

DOI: http://dx.doi.org/10.4314/ejhs.v27i1.4S 
those with or after TB and before or without TB and statistical significance was tested using logrank test. Cox Hazard regression analysis was used to generate adjusted effects of the different factors at the time of death. To avoid survival bias, participants who entered the ACM cohort during or after their date of ART start were entered into the survival analysis late, with delayed entry (leftcensoring) at their date of ACM enrollment. Participants who were terminated from the ACM cohort for a reason other than death were recorded as having left the risk set (right-censored) on their date of termination.

Factors that were statistically significant at $p \leq 0.05$ were considered as potential predictors and were included in the multivariable model. The validity of the proportional hazards model was examined graphically using the Schoenfeld residuals. The 95\% confidence interval for the log hazard ratio was used to measure the association of dependent and independent variables. In addition to identifying the independent predictors, adjusted hazard ratios were used to estimate the magnitude of association. The value and significance level of the intra-site correlation was adjusted for by stratification.

Finally, determinants of survival among patients on ART who developed TB after starting ART were assessed using Cox regression analysis (Fig. $1)$.

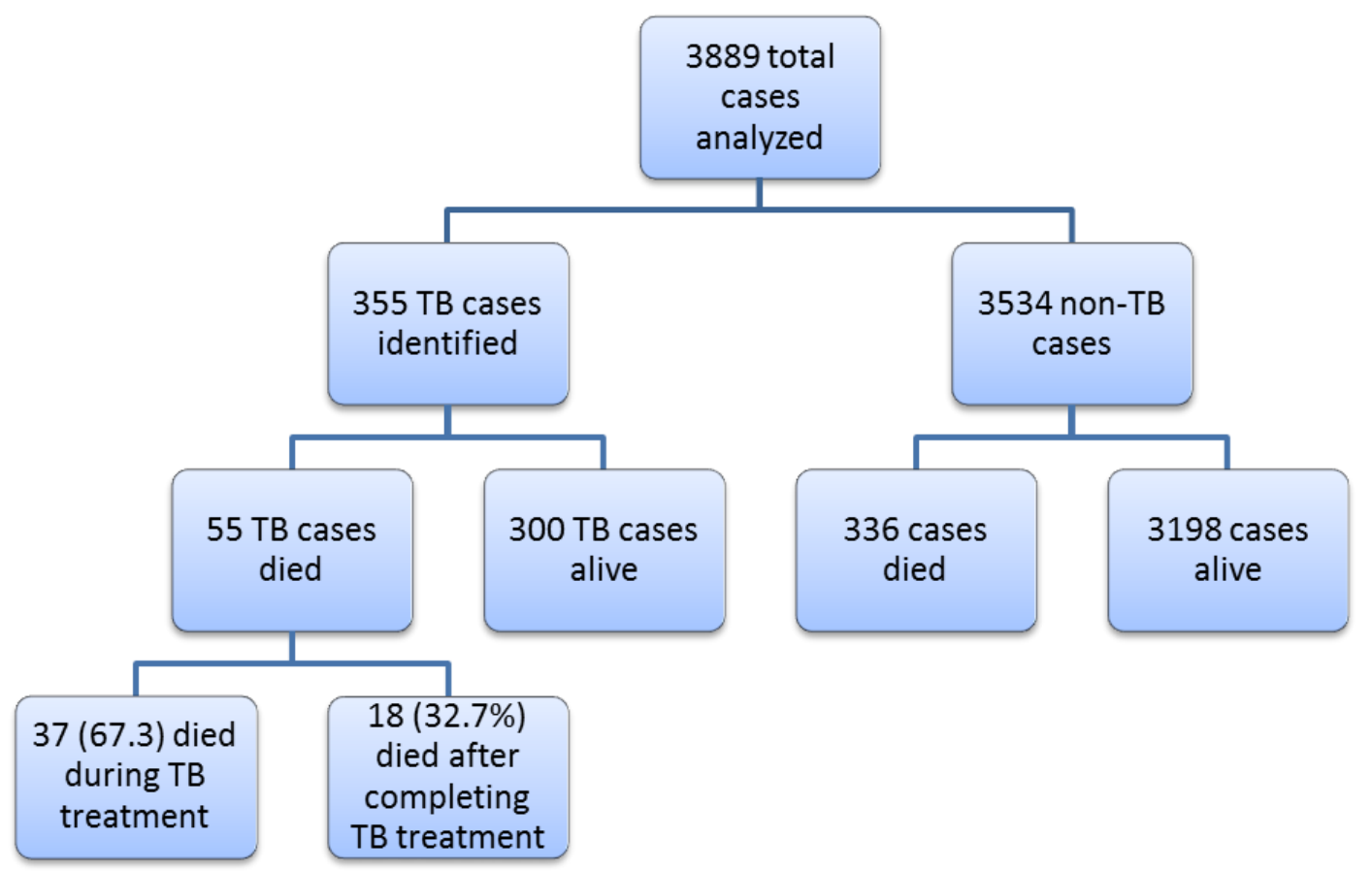

Figure 1. Profile of study subjects, key outcomes and comparisons made.

\section{RESULTS}

Baseline Characteristics: 3,889 HIV patients were analyzed (Fig 1). The median age at enrollment was 32 years (IQR $26-38$ ). Females accounted for $63 \%$ of the sample. Most $(91 \%)$ of the patients were above 15 years of age. Median follow-up time was 1082 days (IQR 382 - 1951); $40 \%$ of the patients on ART were followed for more than four years. The median baseline CD4 cell count at enrollment was $184 / \mathrm{ml}$ (IQR: 86 to 221). A majority of the sample (63\%) had Baseline WHO stage III or IV (Table 1). 
Table 1: Baseline demographic characteristics of participants with TB/HIV co-infection

\begin{tabular}{|c|c|c|c|c|c|c|}
\hline \multirow[t]{2}{*}{ Characteristics } & \multicolumn{2}{|l|}{ Overall } & \multicolumn{2}{|l|}{ Censored } & \multicolumn{2}{|l|}{ Died } \\
\hline & Number & Percent & Number & Percent & Number & Percent \\
\hline \multicolumn{7}{|l|}{ Age } \\
\hline$<15$ & 359 & $9 \%$ & 339 & $10 \%$ & 20 & $5 \%$ \\
\hline$\geq 15$ & 3530 & $91 \%$ & 3159 & $90 \%$ & 371 & $95 \%$ \\
\hline \multicolumn{7}{|l|}{ Sex } \\
\hline Female & 2441 & $63 \%$ & 2231 & $64 \%$ & 210 & $54 \%$ \\
\hline Male & 1448 & $37 \%$ & 1267 & $36 \%$ & 181 & $46 \%$ \\
\hline \multicolumn{7}{|l|}{ Base CD4 Count } \\
\hline$<100$ & 1153 & $30 \%$ & 946 & $27 \%$ & 207 & $53 \%$ \\
\hline $100-350$ & 2561 & $66 \%$ & 2395 & $68 \%$ & 166 & $42 \%$ \\
\hline$\geq 350$ & 175 & $4 \%$ & 157 & $4 \%$ & 18 & $5 \%$ \\
\hline \multicolumn{7}{|l|}{ Base WHO Stage } \\
\hline I -II & 1442 & $37 \%$ & 1365 & $39 \%$ & 77 & $20 \%$ \\
\hline III -IV & 2447 & $63 \%$ & 2133 & $61 \%$ & 314 & $80 \%$ \\
\hline \multicolumn{7}{|l|}{ CTX } \\
\hline No & 324 & $8 \%$ & 272 & $8 \%$ & 52 & $13 \%$ \\
\hline Yes & 3565 & $92 \%$ & 3226 & $92 \%$ & 339 & $87 \%$ \\
\hline \multicolumn{7}{|l|}{ ART Start Year } \\
\hline $2005-2008$ & 1804 & $46 \%$ & 1590 & $45 \%$ & 214 & $55 \%$ \\
\hline $2009-2010$ & 1194 & $31 \%$ & 1090 & $31 \%$ & 104 & $27 \%$ \\
\hline $2011-2013$ & 891 & $23 \%$ & 818 & $23 \%$ & 73 & $19 \%$ \\
\hline \multicolumn{7}{|l|}{ Tuberculosis } \\
\hline No & 3534 & $91 \%$ & 3198 & $91 \%$ & 336 & $86 \%$ \\
\hline Yes & 355 & $9 \%$ & 300 & $9 \%$ & 55 & $14 \%$ \\
\hline Total & 3889 & $100 \%$ & 3498 & $100 \%$ & 391 & $100 \%$ \\
\hline
\end{tabular}

As seen on figure 1 above, The first comparison was between the contribution of TB and non-TB cases for mortality among HIV patients. The second was restricted within TB/HIV cases and it was about identifying variables that were predictors of death among those cases.

TB disease burden: Out of the 3,889 patients follow during 15,328 Person-years, 355 developed TB starting 1st of January 2005, making the crude prevalence in this sample $9 \%(95 \% \mathrm{CI}: 8.3 \%$ $10.2 \%)$. Out of the 355 patients, $24(6.8 \%)$ had extra-pulmonary TB. The median time to diagnose TB was 204 days (IQR:58-698). The overall incidence of TB was 2.19 (95\% CI 1.97-2.43) per 100 person years. The incidence was compared based on duration of ART and the findings are shown in Table 2 below.

Table 2: Tuberculosis (TB) incidence rates according to duration of antiretroviral therapy (per 100 person years).

\begin{tabular}{cccc}
\hline ART Duration (month) & TB Episodes & Person Year at risk & Rate [95\% CI] (per 100 PY) \\
\hline $0-2$ & 93 & 537 & $17.3[14.0$ to 2.13] \\
$2-6$ & 80 & 1087 & $7.4[5.84$ to 9.16$]$ \\
$6-12$ & 38 & 1529 & $2.4[1.76$ to 3.41] \\
$12-24$ & 56 & 2806 & $2.0[1.51$ to 2.59] \\
$>24$ & 88 & 10227 & $0.9[0.69$ to 1.06$]$ \\
Overall & 355 & 16185 & $2.2[1.97$ to 2.43] \\
\hline
\end{tabular}

DOI: http://dx.doi.org/10.4314/ejhs.v27i1.4S 
Incidence was highest in the first two months after ART initiation and declined progressively to 1 per 100 person years after 24 months.

Most patients who developed TB were young adults with $51 \%$ being $15-34$ years of age and female $(54 \%)$. Two thirds had either primary or secondary education, $43 \%$ were married while $34 \%$ were widowed or divorced. Most patients fell in the "working" category of functional status $(60 \%)$ with baseline CD4 count of $<200$ cells $/ \mu \mathrm{L}$ $(75 \%)$, and were WHO Stage III or IV (79\%), received cotrimoxazole $(90 \%)$ at some point during their follow-up, and started with a baseline ART regimen containing nevirapine $(65 \%)$.

Mortality: A total of 391 deaths were recorded in the study cohort resulting in a mortality rate of 2.6 per 100 person-years (95\% CI: $2.3-2.8$ per $100)$. Fifty five $(14 \%)$ deaths were among those who were TB/HIV co-infected. Cotrimoxazole was started for $87 \%$ of those who died. Of these, $95 \%$ were adults (age $\geq 15$ ), $80 \%$ were either WHO stage III or IV, and 53\% had CD4 cell count $<100$.

Table 3: Effect of Tuberculosis on Mortality

\begin{tabular}{|c|c|c|c|c|}
\hline \multirow[t]{2}{*}{ Characteristics } & \multicolumn{2}{|l|}{ Uni-variable analysis* } & \multicolumn{2}{|c|}{ Multi-variable analysis* } \\
\hline & $\begin{array}{l}\text { Hazard ratio } \\
(95 \% \text { CI })\end{array}$ & $\begin{array}{l}\mathbf{P} \\
\text { Value }\end{array}$ & $\begin{array}{l}\text { Hazard ratio } \\
(95 \% \mathrm{CI})\end{array}$ & $\begin{array}{l}\mathbf{P} \\
\text { Value }\end{array}$ \\
\hline \multicolumn{5}{|l|}{ Age } \\
\hline$<15$ & 1 & & & \\
\hline$\geq 15$ & $5.247(2.573-10.70)$ & $<0.001$ & 9.754 (3.001 - 31.70) & $<0.001$ \\
\hline \multicolumn{5}{|l|}{ Sex } \\
\hline Female & 1 & & 1 & \\
\hline Male & $1.340(1.085-1.655)$ & 0.007 & $1.276(1.024-1.590)$ & 0.030 \\
\hline \multicolumn{5}{|l|}{ Base CD4 Count } \\
\hline$<100$ & 1 & & 1 & \\
\hline $100-350$ & $0.456(0.366-0.569)$ & $<0.001$ & $0.525(0.418-0.658)$ & $<0.001$ \\
\hline$\geq 350$ & $0.356(0.175-0.728)$ & 0.005 & $0.731(0.351-1.525)$ & 0.404 \\
\hline \multicolumn{5}{|l|}{ Base WHO Stage } \\
\hline $\mathrm{I}-\mathrm{II}$ & 1 & & 1 & \\
\hline III -IV & $1.618(1.230-2.128)$ & 0.001 & $1.448(1.080-1.941)$ & 0.013 \\
\hline \multicolumn{5}{|l|}{ CTX } \\
\hline No & 1 & & 1 & \\
\hline Yes & $0.600(0.431-0.824)$ & 0.002 & $0.718(0.508-1.013)$ & 0.059 \\
\hline \multicolumn{5}{|l|}{ ART Start Year } \\
\hline $2005-2008$ & 1 & & 1 & \\
\hline $2009-2010$ & $1.110(0.860-1.434)$ & 0.422 & $1.290(0.992-1.679)$ & 0.057 \\
\hline $2011-2013$ & $1.550(1.146-2.094)$ & 0.004 & $1.497(1.427$ - 2.728) & $<0.001$ \\
\hline \multicolumn{5}{|l|}{ Tuberculosis } \\
\hline No & 1 & & 1 & \\
\hline Yes & $2.013(1.473-2.751)$ & $<0.001$ & $1.785(1.289-2.473)$ & $<0.001$ \\
\hline
\end{tabular}

* Stratified by facility and functional status. Functional status strongly predicted mortality but couldn't be used in the model since it violated the proportionality assumption. It is for this reason that it was included in the stratification to adjust for the main predictor.

DOI: http://dx.doi.org/10.4314/ejhs.v27i1.4S 
Association of TB with Mortality: The period of follow-up where patients were diagnosed and received TB treatment was significantly associated with death (crude hazard ratio 2.0 (95\% CI 1.472.75)) as compared to the time that all study participants were free of TB. After adjusting for all available factors, the hazard ratio (HR) was 1.79 (95\% CI 1.29-2.47).

The Kaplan-Meier failure estimate shown in Fig. 2 also shows that those with TB have much higher probability of death.

Table 4: Baseline demographic characteristics of participants with TB/HIV co-infection

\begin{tabular}{|c|c|c|c|c|c|c|}
\hline \multirow[t]{2}{*}{ Characteristics } & \multicolumn{2}{|l|}{ Overall } & \multicolumn{2}{|l|}{ Censored } & \multicolumn{2}{|l|}{ Died } \\
\hline & Number & Percent & Number & Percent & Number & Percent \\
\hline \multicolumn{7}{|l|}{ Age at ART Start } \\
\hline$<15$ & 17 & 4.8 & 15 & 4.7 & 2 & 5.4 \\
\hline$\geq 15$ & 338 & 95.1 & 303 & 95.3 & 35 & 94.5 \\
\hline \multicolumn{7}{|l|}{ Gender } \\
\hline Female & 193 & 54.4 & 181 & 56.9 & 12 & 32.4 \\
\hline Male & 162 & 45.6 & 137 & 43.1 & 25 & 67.6 \\
\hline \multicolumn{7}{|l|}{ Base CD4 Count } \\
\hline$<50$ & 54 & $16.2 \%$ & 47 & $15.8 \%$ & 7 & $18.9 \%$ \\
\hline $50-199$ & 196 & $58.7 \%$ & 174 & $58.6 \%$ & 22 & $59.5 \%$ \\
\hline $200-349$ & 72 & $21.6 \%$ & 65 & $21.9 \%$ & 7 & $18.9 \%$ \\
\hline$>=350$ & 12 & $3.6 \%$ & 11 & $3.7 \%$ & 1 & $2.7 \%$ \\
\hline \multicolumn{7}{|l|}{ Base WHO Stage } \\
\hline I or II & 73 & $21 \%$ & 69 & $22 \%$ & 4 & $11 \%$ \\
\hline III or IV & 279 & $79 \%$ & 247 & $78 \%$ & 32 & $89 \%$ \\
\hline \multicolumn{7}{|l|}{ CTX } \\
\hline Yes & 320 & $90.1 \%$ & 289 & $90.9 \%$ & 31 & $83.8 \%$ \\
\hline No & 35 & $9.9 \%$ & 29 & $9.1 \%$ & 6 & $16.2 \%$ \\
\hline \multicolumn{7}{|l|}{ ART Start Year } \\
\hline $2005-2008$ & 238 & 67.0 & 214 & 67.3 & 24 & 64.9 \\
\hline $2009-2010$ & 96 & 27.0 & 85 & 26.7 & 11 & 29.7 \\
\hline $2011-2013$ & 21 & 5.9 & 19 & 6.0 & 2 & 5.4 \\
\hline \multicolumn{7}{|c|}{ Base Functional Status } \\
\hline Working & 204 & $59.6 \%$ & 189 & $61.6 \%$ & 15 & $42.9 \%$ \\
\hline Ambulatory & 113 & $33.0 \%$ & 99 & $32.2 \%$ & 14 & $40.0 \%$ \\
\hline Bedridden & 25 & $7.3 \%$ & 19 & $6.2 \%$ & 6 & $17.1 \%$ \\
\hline \multicolumn{7}{|l|}{ Facility } \\
\hline Tikur Anbessa & 44 & 12.4 & 39 & 12.3 & 5 & 13.5 \\
\hline ARMY & 52 & 14.6 & 42 & 13.2 & 10 & 27.0 \\
\hline Gondar & 55 & 15.5 & 51 & 16.0 & 4 & 10.8 \\
\hline Jimma & 57 & 16.1 & 52 & 16.4 & 5 & 13.5 \\
\hline Mekelle & 42 & 11.8 & 37 & 11.6 & 5 & 13.5 \\
\hline Haramaya & 54 & 15.2 & 50 & 15.7 & 4 & 10.8 \\
\hline Hawassa & 51 & 14.4 & 47 & 14.8 & 4 & 10.8 \\
\hline Total & 355 & & 318 & 100.0 & 37 & 100.0 \\
\hline
\end{tabular}

DOI: http://dx.doi.org/10.4314/ejhs.v27i1.4S 


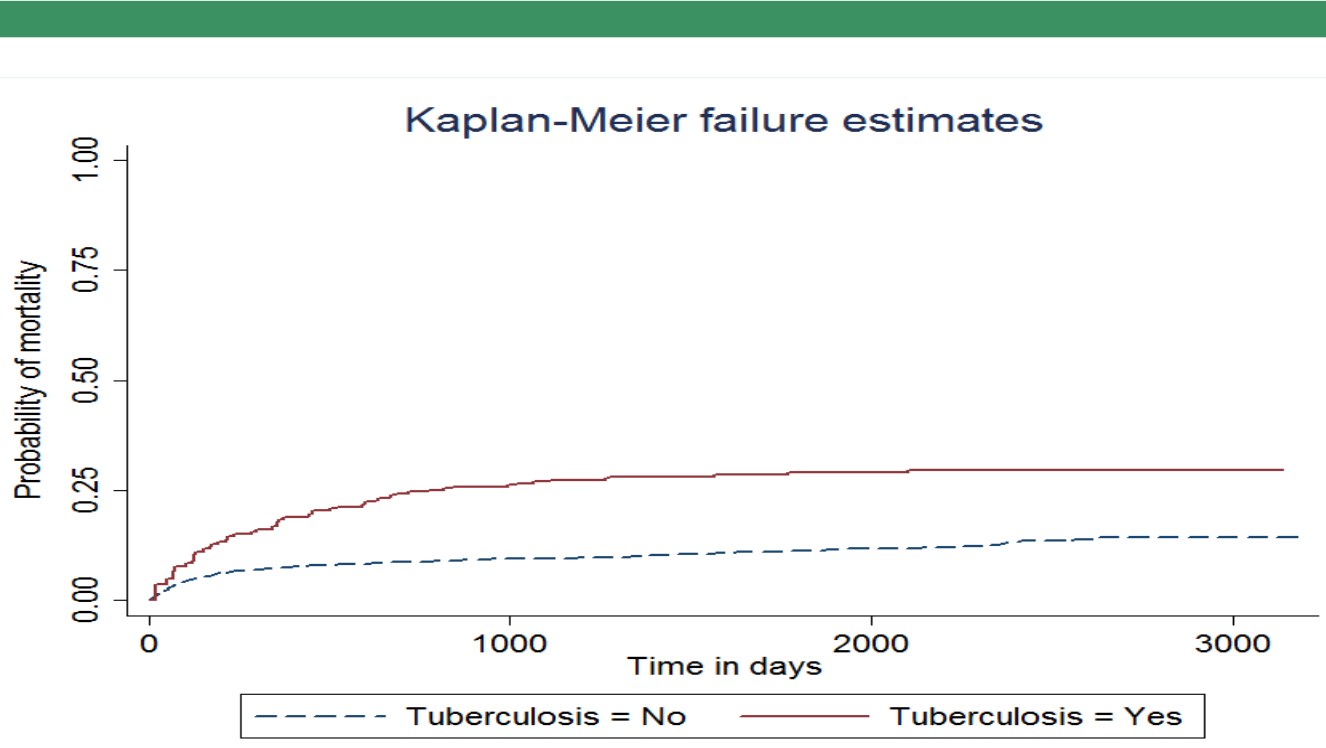

Fig 2: Kaplan-Meier failure curves for time to death by TB status (Log-rank test $\mathrm{P}<0.0001$ )

Predictors of survival among those with TB/HIV co-infection: During uni-variable analysis, being older age, male, enrolled in the early study period, earlier diagnosis of TB after enrollment, and being bedridden at enrollment were all significantly associated with the occurrence of death among HIV patients on ART co-infected with TB. However, in the multivariable Cox-regression analysis, only gender and time to $\mathrm{TB}$ diagnosis remained statistically significant.

Table 5: Determinants of survival of TB/HIV co-infected patients.

\begin{tabular}{|c|c|c|c|c|}
\hline \multirow[t]{2}{*}{ Characteristics } & \multicolumn{2}{|l|}{ Uni-variable analysis } & \multicolumn{2}{|l|}{ Multi-variable analysis } \\
\hline & Hazard ratio(95\% CI) & P-Value & Hazard ratio $(95 \% \mathrm{CI})$ & P-Value \\
\hline Age (In Years) & $1.033(1.002-1.065)$ & 0.04 & $1.030(0.996-1.066)$ & 0.084 \\
\hline \multicolumn{5}{|l|}{ Sex } \\
\hline Female & 1 & & 1 & \\
\hline Male & $2.622(1.317-5.220)$ & 0.006 & $2.131(1.028-4.414)$ & 0.042 \\
\hline TB Start Year & $0.798(0.668-0.952)$ & 0.012 & $1.049(0.878-1.253)$ & 0.600 \\
\hline Time To TB diagnosis & $0.993(0.990-0.996)$ & 0.000 & $0.993(0.989-0.996)$ & 0.000 \\
\hline Base CD4 Count & $0.998(0.994-1.001)$ & 0.208 & & \\
\hline \multicolumn{5}{|l|}{ Base WHO Stage } \\
\hline $\begin{array}{l}\text { I-II } \\
\text { III -IV }\end{array}$ & $\begin{array}{l}1 \\
1.947(0.687-5.516)\end{array}$ & 0.210 & & \\
\hline \multicolumn{5}{|l|}{ Base Functional Status } \\
\hline Working & 1 & & 1 & \\
\hline Bedridden/Ambulatory & $2.152(1.100-4.208)$ & 0.025 & $1.876(0.933-3.771)$ & 0.078 \\
\hline \multicolumn{5}{|l|}{ CTX } \\
\hline Yes & 1 & & & \\
\hline No & $1.766(0.737-4.235)$ & 0.202 & & \\
\hline
\end{tabular}

DOI: http://dx.doi.org/10.4314/ejhs.v27i1.4S 


\section{DISCUSSION}

Mortality in the study cohort was 2.6 per 100 PY. This was more or less similar to other studies from Ethiopia (12, 13). Mortality in TB/HIV coinfected patients in Ethiopia remains high compared to those without co-infection (3, 14-16). Several factors have been identified to contribute to high mortality. However, a particular group of TB/HIV co-infected people at risk for mortality have not previously been identified. In this study, we examined this specific gap in knowledge among HIV patients on ART in seven teaching university hospitals in Ethiopia. The study found TB to be prevalent $(8 \%)$ in the study population while the incidence was 2.2 per 100 person years of follow-up. This finding was similar to recent studies, but lower than previous estimates that were made at the start of ART program $(17,18)$. The incidence of TB was highest in the first two months after initiation of ART and declined with longer duration on ART. The incidence remained high even after 24 months as compared to those who were free of HIV. Three hundred ninety one patients died during follow-up. The TB-associated death was $15 \%$. Tuberculosis was significantly associated with mortality among HIV patients on HAART compared to the duration when patients didn't have TB: hazard ratio of 2.0 (95\% CI 1.472.75) after adjusting for baseline clinical and demographic characteristics. Tuberculosis associated mortality was twice as much in men as in women and higher in the early period after ART initiation.

The prevalence $(8 \%)$ and incidence $(2.2$ per 100 person year) of TB observed in this study is comparable with findings by Assefa et al and Yirdaw et al $(17,19)$ but was lower than that reported in other settings in Addis Ababa, Gondar and Dire Dawa (20-22) with incidence ranging from 3.3 to 7.9 per $100 \mathrm{PY}$. The association of TB incidence with duration of ART was also reported in other studies $(19,22,23)$. Typically most of the cases appear in the first six months, decreasing thereafter. Some of these declines are associated with immune reconstitution inflammatory syndrome and in all settings, incidence declined as the immune status recovered with ART.

Association of TB with mortality was demonstrated in studies by Setegn et al, Bane et al, and Aragie et al. (21, 24, 25). Tuberculosis associated mortality typically coincided with peak periods of TB diagnosis. In this current study, we showed that most TB related deaths were observed in the first six months of ART. In our cohort, the important determinants of death in the first six months were: having CD4 cell count below 100, having other AIDS defining conditions, not receiving cotrimoxazole, and being on treatment after 2010. These findings are in agreement with Setegn et al (24). The fact that mortality increased in the later years of treatment where quality of care is expected to be better is paradoxical and warrants further investigation.

The determinants of mortality among TB/HIV coinfected patients on ART in Ethiopia were reported in two previous studies. The first was carried out in southwestern Ethiopia with an unmatched case-control design. Results showed that being male, bed ridden and having a cough for more than two weeks at enrollment were independent predictors of mortality (26). The second study was a randomized controlled trial by Amogne et al (28); results indicated having lower BMI, serum albumin $<3 \mathrm{gms} / \mathrm{dl}$ and baseline CD4 count of below 50 cells $/ \mu \mathrm{L}$ were determinants of mortality. The association of gender, and to some extent functional status, found in the current study is supported by findings from the first study(27). In the Amongne study, all patients were first diagnosed as TB and later started on ART at one, four and eight week intervals. Hence, a direct comparison with our study is not possible. The overall mortality was $10 \%$ at the end of that study (48 weeks) was lower than the mortality in this study (15\%). Findings of mortality from most observational studies carried out in Ethiopia are in agreement with the current study with values ranging from 15 to $18 \%(24,28,29)$.

This current study provides more insight into the importance of the first few months after starting ART treatment on the quality of life of patients with TB/HIV co-infection. This is the period with high likelihood of occurrence of TBrelated morbidity and mortality. Investing maximum effort at this high risk time ensures delivery of high quality TB screening and subsequent treatment and support leading to improved survival. In addition, particular subgroups of PLHIV identified in this study could

DOI: http://dx.doi.org/10.4314/ejhs.v27i1.4S 
be used to target service delivery to obtain maximum benefit from intervention programs.

This is one of the few prospective longitudinal studies showing occurrence of TB coinfection with HIV and associated mortality. Even though most of our findings were comparable to other observational studies based on secondary data, this study's results support findings from routine program reports that say what? These can be used for planning and direct program implementation. This study, however, has some important limitations. The diagnosis of TB was not confirmed with sputum culture and hence may be an underestimation of the true prevalence or incidence as sputum AFB has low sensitivity (14). The viral load also was not determined which may have been used to refine models for predicting morbidity and mortality.

In conclusion, TB was found to be important contributor for HIV-associated mortality among PLHIV on ART. Targeting interventions in the first few months after ART initiation may have a greater impact on reducing TB/HIV related mortality than beginning treatment later in the disease process.

\section{DISCLAIMER}

The findings and conclusions in this report are those of the author(s) and do not necessarily represent the official position of the Centers for Disease Control and Prevention.

\section{ACKNOWLEDGMENT}

The Research has been supported by the President's Emergency Plan for AIDS Relief (PEPFAR) through the Centers for Disease Control and Prevention (CDC) under the terms of Cooperative Agreement with Johns Hopkins School of Public health number PS000858.

\section{REFERNCES}

1. World Health Organisation. Consolidated guidelines on the use of antiretroviral drugs for treating and preventing HIV infection: recommendations for a public health approach. Geneva, Switzerland2013.

2. World Health Organisation. Global Tuberculosis Control Report 2010. Geneva, Switzerland. 2010.
3. World Health Organization. Global Tuberculosis Report 2014. 2014.

4. World Health Organisation. Antiretroviral therapy for HIV infection in adults and adolescents: recommendations for a public health approach- 2010 revision. 2010.

5. Federal Ministry of Health. Health Sector Annual Performance Report. 2014.

6. Agbor AA, Bigna JJR, Billong SC, Tejiokem MC, Ekali GL, Plottel CS, et al. Factors Associated with Death during Tuberculosis Treatment of Patients Co-Infected with HIV at the Yaoundé Central Hospital, Cameroon: An 8Year Hospital-Based Retrospective Cohort Study (2006-2013). PloS one. 2014;9(12):e115211.

7. Pepper DJ, Schomaker M, Wilkinson RJ, de Azevedo V, Maartens G. Independent predictors of tuberculosis mortality in a high HIV prevalence setting: a retrospective cohort study. AIDS research and therapy. 2015;12(1):1-9.

8. Bigna JJR, Noubiap JJN, Agbor AA, Plottel CS, Billong SC, Ayong APR, et al. Early Mortality during Initial Treatment of Tuberculosis in Patients Co-Infected with HIV at the Yaoundé Central Hospital, Cameroon: An 8-Year Retrospective Cohort Study (2006-2013). PloS one. 2015;10(7):e0132394.

9. Abay SM, Deribe K, Reda AA, Biadgilign S, Datiko D, Assefa T, et al. The Effect of Early Initiation of Antiretroviral Therapy in TB/HIV Coinfected Patients A Systematic Review and Meta-Analysis. Journal of the International Association of Providers of AIDS Care (JIAPAC). 2015:2325957415599210.

10. Subbarao S, Wilkinson KA, Van Halsema CL, Rao SS, Boyles T, Utay NS, et al. Raised Venous Lactate and Markers of Intestinal Translocation Are Associated With Mortality Among In-Patients With HIV-Associated TB in Rural South Africa. JAIDS Journal of Acquired Immune Deficiency Syndromes. 2015;70(4):406-13.

11. Federal Ministry of Health. Guideline for clinical and Programatic management of TB, TB/HIV and Leprosy in Ethiopia. FIFTH ed. Addis Ababa, Ethiopia2013.

12. Edessa D, Likisa J. A Description of Mortality Associated with IPT plus ART Compared to ART Alone among HIV-Infected Individuals in Addis Ababa, Ethiopia: A Cohort Study. PloS one. 2015;10(9):e0137492.

DOI: http://dx.doi.org/10.4314/ejhs.v27i1.4S 
13. Damtew B, Mengistie B, Alemayehu T. Survival and determinants of mortality in adult HIV/Aids patients initiating antiretroviral therapy in Somali Region, Eastern Ethiopia. Journal of AIDS \& Clinical Research. 2014;2014.

14. Federal Ministry of Health Ethiopian Health and Nutrition Research Institute. First Ethiopian national population based TB prevalence survey. Ethiopia. . 2011.

15. Zheng Z, Cui Z, Huang M, Pan D. (Effect of antiretroviral therapy in reducing deaths among patients co-infected with Mycobacterium tuberculosis and human immunodeficiency virus in Guangxi). Zhonghua liu xing bing xue za zhi= Zhonghua liuxingbingxue zazhi. 2015;36(2):124-7.

16. Gesesew H, Tsehaineh B, Massa D, Tesfay A, Kahsay H, Mwanri L. The role of social determinants on tuberculosis/HIV co-infection mortality in southwest Ethiopia: a retrospective cohort study. BMC research notes. 2016;9(1):1.

17. Yirdaw KD, Jerene D, Gashu Z, Edginton M, Kumar AM, Letamo Y, et al. Beneficial Effect of Isoniazid Preventive Therapy and Antiretroviral Therapy on the Incidence of Tuberculosis in People Living with HIV in Ethiopia. PloS one. 2014;9(8):e104557.

18. Jerene D, Næss A, Lindtjørn B. Antiretroviral therapy at a district hospital in Ethiopia prevents death and tuberculosis in a cohort of HIV patients. AIDS Research and Therapy. 2006;3(1):10.

19. Assefa A, Gelaw B, Getnet G, Yitayew G. The effect of incident tuberculosis on immunological response of HIV patients on highly active antiretroviral therapy at the university of Gondar hospital, northwest Ethiopia: a retrospective follow-up study. BMC infectious diseases. 2014;14(1):468.

20. Alene KA, Nega A, Taye BW. Incidence and predictors of tuberculosis among adult people living with human immunodeficiency virus at the University of Gondar Referral Hospital, Northwest Ethiopia. BMC infectious diseases. 2013;13(1):292.

21. Kassa A, Teka A, Shewaamare A, Jerene D. Incidence of tuberculosis and early mortality in a large cohort of HIV infected patients receiving antiretroviral therapy in a tertiary hospital in Addis Ababa, Ethiopia. Transactions of the Royal Society of Tropical Medicine and Hygiene. 2012;106(6):363-70.
22. Assefa D, Melaku Z, Gadissa T, Negash A, Hinderaker S, Harries A. Intensified tuberculosis case finding among people living with the human immunodeficiency virus in a hospital clinic in Ethiopia (Notes from the field). The International Journal of Tuberculosis and Lung Disease. 2011;15(3):411-3.

23. Gupta A, Wood R, Kaplan R, Bekker L-G, Lawn SD. Tuberculosis incidence rates during 8 years of follow-up of an antiretroviral treatment cohort in South Africa: comparison with rates in the community. PloS one. 2012;7(3):e34156.

24. Setegn T, Takele A, Gizaw T, Nigatu D, Haile D. Predictors of Mortality among Adult Antiretroviral Therapy Users in Southeastern Ethiopia: Retrospective Cohort Study. AIDS research and treatment. 2015;2015.

25. Bane A, Yohannes A, Fekade D. Morbidity and mortality of adult patients with HIV/AIDS at Tikur Anbessa Teaching Hospital, Addis Ababa, Ethiopia. Ethiopian medical journal. 2003;41(2):131-40.

26. Deribe K, Yami A, Deribew A, Mesfin N, Colebunders R, Woldie M, et al. Predictors of Mortality among Tuberculosis-HIV-Coinfected Persons in Southwest Ethiopia A Case-Control Study. Journal of the International Association of Providers of AIDS Care (JIAPAC). 2013:2325957413500528.

27. Wondwosen Amogne GA, Abiy Habtewold, Getnet Yimer, Eyasu Makonnen, Alemayhu Worku, Anders Sonnerborg, Eleni Aklillu, Lars Lindquist. Efficacy and Safety of Antiretroviral Therapy Initiated One Week after Tuberculosis Therapy in Patients with CD4 Counts < 200 Cells/ $\mu$ L: TB-HAART Study, a Randomized Clinical Trial. PLoS ONE 10(5):e0122587 doi:101371/journalpone0122587. 2015.

28. Shaweno D, Worku A. Tuberculosis treatment survival of HIV positive TB patients on directly observed treatment short-course in Southern Ethiopia: A retrospective cohort study. BMC research notes. 2012;5(1):682.

29. Sileshi B, Deyessa N, Girma B, Melese M, Suarez P. Predictors of mortality among TBHIV Co-infected patients being treated for tuberculosis in Northwest Ethiopia: a retrospective cohort study. BMC infectious diseases. 2013;13(1):297. 